\title{
Teaching NeuroImages: Spinal xanthomatosis
}

\section{A misdiagnosed, treatable cause of progressive myelopathy}

Cristina Valencia-Sanchez, MD, Dean M. Wingerchuk, MD, and Radhika Dhamija, MD

Neurology ${ }^{\circledR}$ 2020;95:e1615-e1616. doi:10.1212/WNL.0000000000010194

Figure 1 Photograph of the patient's Achilles tendons

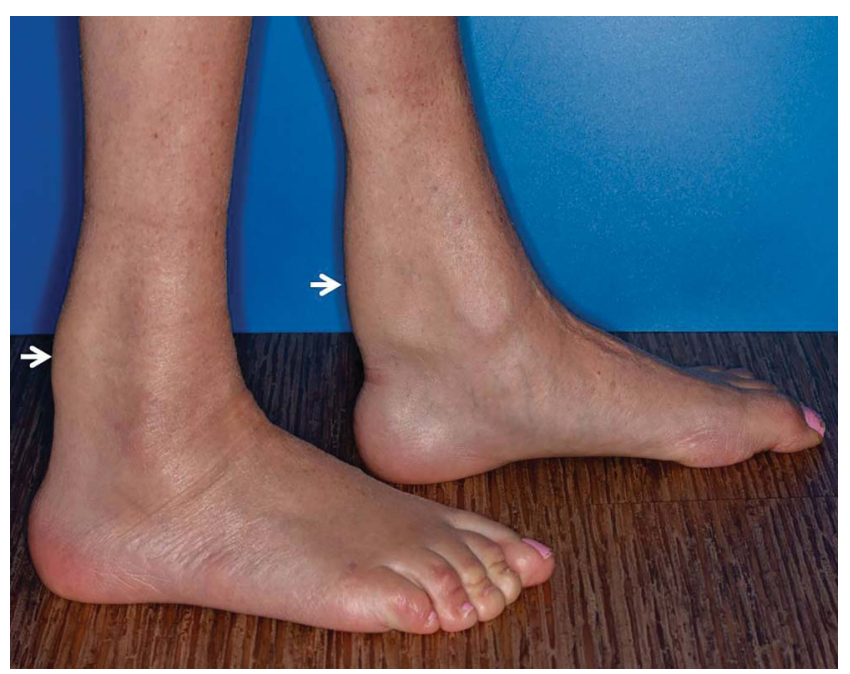

Enlargement of Achilles tendons bilaterally was suggestive of tendon xanthomas.

A 57-year-old woman presented with a 20-year history of progressive lower extremity weakness, spasticity, and proprioception deficits. She was given a diagnosis of primary progressive multiple sclerosis at age 38. Her Achilles tendons were enlarged (figure 1). Brain MRI was normal. Spine MRI demonstrated T2-hyperintense signal involving the posterior and lateral columns (figure 2). Serum cholestanol level was elevated. CYP27A1 gene sequencing revealed 2 pathogenic variants, c.1183C > T(p.Arg395Cys) and c.410G >A(p.Arg137Gln), confirming the diagnosis of cerebrotendinous xanthomatosis (CTX). Spinal xanthomatosis is a rare variant of CTX presenting with progressive corticospinal and posterior column signs. ${ }^{1}$ Early treatment with chenodeoxycholic acid may improve outcomes. ${ }^{2}$

\section{Study funding}

No targeted funding reported.

\section{Disclosure}

The authors report no disclosures relevant to this manuscript. Go to Neurology.org/N for full disclosures.

\section{Correspondence}

Dr. Dhamija

dhamija.radhika@mayo.edu

\section{MORE ONLINE}

$\rightarrow$ Teaching slides

lww.com/WNL/B158 
Figure 2 Spinal MRI

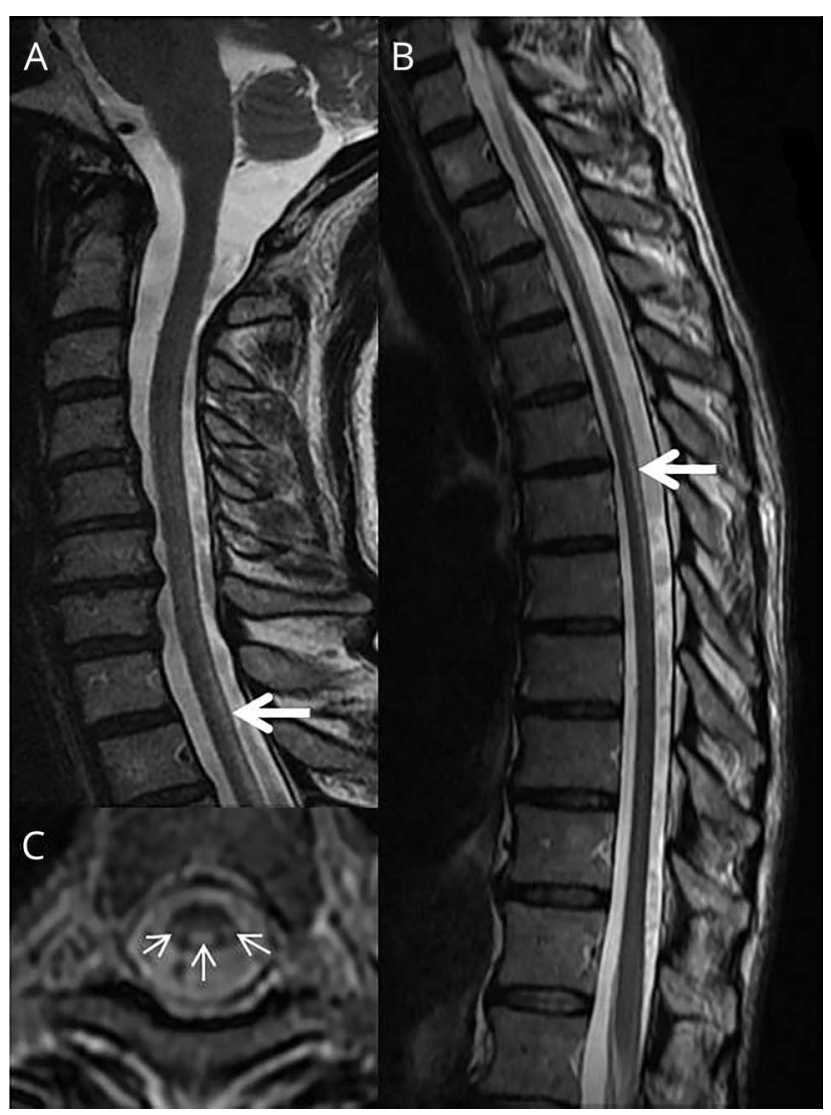

T2-weighted cervical sagittal (A), thoracic sagittal (B), and axial (C) images demonstrate T2-hyperintense signal abnormality involving the posterior and lateral columns from C2 to T8-T9.
Appendix Authors

\begin{tabular}{lll}
\hline Name & Location & Contribution \\
\hline $\begin{array}{l}\text { Cristina } \\
\text { Valencia- } \\
\text { Sanchez, MD }\end{array}$ & $\begin{array}{l}\text { Mayo Clinic, } \\
\text { Phoenix, AZ }\end{array}$ & $\begin{array}{l}\text { Case concept and design, acquisition } \\
\text { and interpretation of data, manuscript } \\
\text { writing }\end{array}$ \\
\hline $\begin{array}{l}\text { Dean M. } \\
\text { Wingerchuk, } \\
\text { MD }\end{array}$ & $\begin{array}{l}\text { Mayo Clinic, } \\
\text { Phoenix, AZ }\end{array}$ & $\begin{array}{l}\text { Case concept and design, } \\
\text { interpretation of data, critical revision } \\
\text { of manuscript for intellectual content }\end{array}$ \\
\hline $\begin{array}{l}\text { Rhadika } \\
\text { Dhamija, MD }\end{array}$ & Mayo Clinic, & $\begin{array}{l}\text { Case concept and design, acquisition } \\
\text { and interpretation of data, critical } \\
\text { revision of manuscript for intellectual } \\
\text { content }\end{array}$ \\
\hline
\end{tabular}

\section{References}

1. Verrips A, Nijeholt GJ, Barkhof F, et al. Spinal xanthomatosis: a variant of cerebrotendinous xanthomatosis. Brain 1999;122:1589-1595.

2. Stelten BML, Huidekoper HH, van de Warrenburg BPC, et al. Long-term treatment effect in cerebrotendinous xanthomatosis depends on age at treatment start. Neurology 2019;92:e83-e95. 


\section{Neurology}

\section{Teaching NeuroImages: Spinal xanthomatosis: A misdiagnosed, treatable cause of progressive myelopathy}

Cristina Valencia-Sanchez, Dean M. Wingerchuk and Radhika Dhamija

Neurology 2020;95;e1615-e1616 Published Online before print July 7, 2020

DOI 10.1212/WNL.0000000000010194

This information is current as of July 7, 2020

\section{Updated Information \&} Services

References

Subspecialty Collections

Permissions \& Licensing

Reprints including high resolution figures, can be found at: http://n.neurology.org/content/95/11/e1615.full

This article cites 2 articles, 1 of which you can access for free at: http://n.neurology.org/content/95/11/e1615.full\#ref-list-1

This article, along with others on similar topics, appears in the following collection(s):

\section{All Genetics}

http://n.neurology.org/cgi/collection/all_genetics

All Medical/Systemic disease

http://n.neurology.org/cgi/collection/all_medical_systemic_disease All Spinal Cord

http://n.neurology.org/cgi/collection/all_spinal_cord

Information about reproducing this article in parts (figures,tables) or in its entirety can be found online at:

http://www.neurology.org/about/about_the_journal\#permissions

Information about ordering reprints can be found online:

http://n.neurology.org/subscribers/advertise

Neurology ${ }^{\circledR}$ is the official journal of the American Academy of Neurology. Published continuously since 1951, it is now a weekly with 48 issues per year. Copyright () 2020 American Academy of Neurology. All rights reserved. Print ISSN: 0028-3878. Online ISSN: 1526-632X.

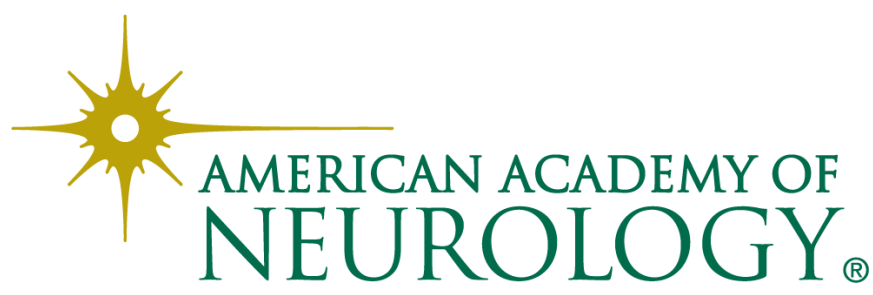

